\title{
Office-Based Unsedated Ultrathin Esophagoscopy in a Primary Care Setting
}

\author{
Thad Wilkins, MD \\ Ralph A. Gillies, PbD \\ Department of Family Medicine, Medical \\ College of Georgia, Augusta, Ga

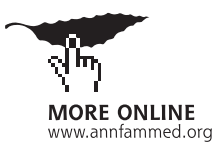

Conflicts of interest: none reported

\section{CORRESPONDING AUTHOR}

Thad Wilkins, MD

Medical College of Georgia, HB-4031

Augusta, GA 30912

twilkins@mcg.edu

\begin{abstract}
PURPOSE Gastroesophageal reflux disease is common and with time may be complicated by Barrett's esophagus and esophageal adenocarcinoma. Upper gastrointestinal endoscopy, including esophagoscopy, is the procedure of choice to diagnose Barrett's esophagus and other esophageal disease. The use of unsedated ultrathin esophagoscopy (UUE) has been reported by gastroenterologists in specialized endoscopy units and otolaryngologists in outpatient otolaryngology offices, but UUE has not been previously described in a primary care setting. This study examines the feasibility of office-based UUE in primary care.
\end{abstract}

METHODS This study is a retrospective chart review in a university-based family medicine clinic in the southeastern United States. Charts were reviewed of 56 adult outpatients who were referred for further evaluation of reflux symptoms that persisted after at least 4 weeks of therapy with histamine 2 receptor agonists or proton pump inhibitors and who elected to undergo UUE in the primary care setting. Patient demographics, procedure indications and findings, changes in clinical management, and procedure times were recorded.

RESULTS One hundred percent of patients asked to participate in UUE were willing to undergo the procedure (mean age $48.3 \pm 1.6 \mathrm{y}, 57.1 \%$ women); $95 \%$ of the patients tolerated UUE. Barrett's esophagus was diagnosed in $5.7 \%(n=3)$ of the patients. Mean procedure time was $5.5 \pm 1.7 \mathrm{~min}$. No complications were reported in this series.

CONCLUSIONS Initial data suggest that UUE is feasible in primary care, with the majority of patients tolerating the procedure. UUE may be an efficient method of examining the distal esophagus.

Ann Fam Med 2005;3:126-130. DOI: 10.1370/afm.262.

\section{INTRODUCTION}

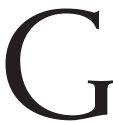
astroesophageal reflux disease (GERD) is a chronic disease encountered in primary care and requires lifelong therapy in as many as $50 \%$ of patients. ${ }^{1}$ Barrett's esophagus is a complication of chronic GERD found in approximately $10 \%$ of patients undergoing upper gastrointestinal endoscopies for GERD. ${ }^{2}$ Chronic GERD and Barrett's esophagus are risk factors for esophageal adenocarcinoma, which has one of the lowest cancer cure rates $(10 \%))^{3}$ Screening strategies for esophageal cancer have therefore focused on identifying Barrett's esophagus through upper gastrointestinal endoscopies in patients with chronic GERD symptoms. Surveillance endoscopy in patients with Barrett's esophagus has been associated with earlier detection of esophageal cancer and improved survival. ${ }^{4}$

Recent advances in technology have led to the development of an ultrathin video esophagoscope that can be introduced either orally or nasally in an unsedated patient to visualize the esophagus and gastroesophageal junction. A thinner and more flexible scope may decrease patient discomfort and enhance overall tolerability of an unsedated examination. Unsedated ultrathin esophagoscopy (UUE) has been used to define patho- 
logic findings in patients with dysphagia ${ }^{5}$ and head and neck cancers, ${ }^{6}$ to identify esophageal varices, ${ }^{7}$ and to screen for Barrett's esophagus. ${ }^{8-12}$ UUE has a sensitivity of $75 \%$ to $91 \%$ and a specificity $98 \%$ to $99 \%$ for esophageal lesions, eg, hiatal hernia and esophagitis. ${ }^{9,12}$ For diagnosis of Barrett's esophagus, UUE has a sensitivity of $89 \%$ to $100 \%$ and a specificity of $96 \%$ to $100 \% .{ }^{9,12}$ Tolerability of intubating the esophagus and visualizing the mucosa clearly is excellent with UUE (95\% to $100 \%)$. $^{5,13,14}$ Additionally, the feasibility of UUE has been reported by gastroenterologists and otolaryngologists. ${ }^{7,13}$ One study reported the feasibility and accuracy of UUE for esophageal screening by nurse practioners. ${ }^{12}$ From our review of the literature, this report is the first describing the experience of a family physician with UUE. The primary aim of this study was to show the feasibility of a family physician performing UUE in a primary care clinic.

\section{METHODS}

A retrospective chart review was conducted examining the medical records of 56 adult outpatients older than 18 years at a southeastern US primary care clinic. The study was approved by the Institutional Review Board of the Medical College of Georgia. Patients with persistent reflux symptoms after at least 4 weeks of therapy with histamine ${ }_{2}\left(\mathrm{H}_{2}\right)$-receptor blockers or proton pump inhibitors who were referred from family medicine colleagues to the author (TW) between June 2003 and July 2004 were eligible for the study. Family medicine colleagues were likely to discuss diagnostic options with their patients before referral, including a discussion of UUE. Patients with daily abdominal pain or nausea or history of peptic ulcer disease were excluded. No other exclusionary criteria were used. Patients were offered all available diagnostic options including sedated conventional esophagogastroduodenoscopy (EGD), unsedated ultrathin EGD, barium swallow, referral to specialist, and UUE. The Supple-

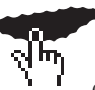
mental Appendix, which can be found online only at http://www.annfammed.org/cgi/content/ full/3/2/126/DC1, describes the technique of UUE. The endoscopist (TW) is a board-certified family physician who has performed upper endoscopy independently for 6 years, is credentialed in EGD, has 5 years' experience in unsedated EGD, and performs EGDs 2.5 days per week, as well as being credentialed in nasolaryngoscopy, which has a similar outer diameter and operating characteristics of the ultrathin esophagoscope. We reviewed the chart records for demographic data, indications for UUE, endoscopic diagnosis, procedure and transition time, whether retroflexion was completed, and changes in treatment. Complications,

\section{Figure 1. Ultrathin endoscope, XEF-140Y1.}

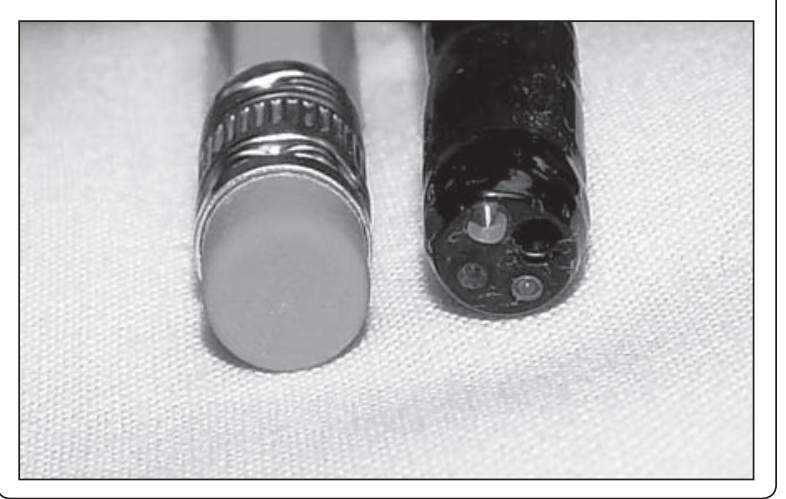

such as bleeding, infections, epistaxis, perforation, syncope, or vasovagal reactions, were noted.

UUE was completed as part of a medical evaluation using a XEF-140Y1 gastrointestinal videoscope (Olympus America, Inc, Melville, NY) (Figure 1). The XEF$140 \mathrm{Y} 1$ has an outer diameter of $4.0 \mathrm{~mm}$ at the insertion tube, a working length of $600 \mathrm{~mm}$, a bending section of upward 180 degrees and downward 90 degrees (with no right or left deflection), and a field of view of 120 degrees. The endoscope has air and water for insufflation and flushing the objective lens. The XEF-140Y1 endoscope does not have an accessory channel for biopsy, nor does it not require special cleaning techniques or equipment to disinfect $t_{i}$ it can be cleaned in the usual manner.

\section{Data Analysis}

The primary analyses for the study were the evaluation of frequencies, percentages, and means of study variables, including endoscopy completion rates and the prevalence of findings. SPSS software version 11 (SPSS Inc, Chicago, Ill) was used for all analyses.

\section{RESULTS}

Fifty-six (100\%) patients who were asked to undergo UUE were willing to do so. The mean age of the patients in the study was $48.3 \pm 1.6$ years, $57.1 \%$ were women, 28.6\% were African American, 69.6\% were white non-Hispanic, and $1.8 \%$ were of other racial categories. The payer status in this chart review was $64.3 \%$ private insurance, $14.3 \%$ Medicare, $12.5 \%$ Medicaid, and $8.9 \%$ self-pay.

Tolerability of UUE was excellent in our case series, with 53 patients $(94.6 \%)$ completing UUE. Three patients $(5.4 \%)$ elected not to continue within the first 1 to 2 minutes of the procedure because of severe gagging and retching; these 3 patients were referred for a sedated EGD. A retroflexion maneuver was carried out 
on $51(96 \%)$ of the 53 patients who completed UUE. Retroflexion was not completed in the remaining 2 patients secondary to increased retching and decreased maneuverability of the endoscope. No complications occurred during this case series.

The mean procedure time was $5.5 \pm 1.7$ minutes. The average transition time from the conclusion of the procedure to patient readiness to hear results was $2.2 \pm$ 1.3 minutes. Activities during transition time included sitting up, taking off the gown worn over clothes, and moving to a chair. Most, $46(86.7 \%)$, UUEs were completed by the oral route, and 7 (13.2\%) were completed by the nasal route.

The most common endoscopic findings were hiatal hernia $(69.8 \%)$, esophagitis $(30.2 \%)$, and reflux laryngitis (13.7\%). Three patients (5.7\%) had Barrett's esophagus diagnosed, and all cases were confirmed with biopsy at a subsequent EGD. In $73.6 \%$ of patients, at least 1 change in the clinical management was made based on findings from UUE. For most patients, this change included the addition of a proton pump inhibitor to their treatment plan. UUE indications, findings, and clinical management are summarized in Table 1.

\section{DISCUSSION}

All patients $(100 \%)$ in our case series were willing to undergo UUE, in contrast with other studies that had acceptance rates ranging from $53 \%$ to $81 \%{ }^{10,12,14} \mathrm{We}$ speculate that our higher acceptance rate was because our procedure was offered in a primary care clinic, where patients did not expect sedated procedures, which are commonly or exclusively offered in specialized endoscopy units. We also believe that patients had anticipated an unsedated upper endoscopic procedure as discussed by their primary care provider, which may have favorably affected our acceptance rate.

The UUE completion rate in this case series, ie, tolerability, was $95 \%$. Of the patients that had a completed UUE, 90.6\% did not require additional endoscopy beyond UUE. Advantages of UUE include minimal loss of time (brief procedure with short recovery time), and patients were able to return to work or drive immediately after the UUE. Disadvantages of UUE compared with standard diameter endoscopy include a narrow field of view, less maneuverability, and lack of biopsy or suction capability. Other potential disadvantages include missed diagnosis, including Schatzki's rings and esophageal erosions. ${ }^{12}$ A technology report describing the first generation of ultrathin endoscopes discussed the incorporation of a color wheel that was more susceptible to image distortions, such as strobing, than the color chip used by full-size standard endoscopes. ${ }^{15}$ The newer ultrathin technology used in this study uses a
Table 1. Unsedated Ultrathin Esophagoscopy Indications, Findings, and Clinical Management

\begin{tabular}{|c|c|c|}
\hline & Number & Percent \\
\hline \multicolumn{3}{|l|}{ Indications ( $\mathrm{n}=56$ ) } \\
\hline Heartburn & 53 & 94.6 \\
\hline Dysphagia & 7 & 12.5 \\
\hline Odynophagia & 5 & 8.9 \\
\hline Chronic hoarseness & 5 & 8.9 \\
\hline Globus sensation & 3 & 5.4 \\
\hline Chest pain & 2 & 3.6 \\
\hline More than 1 indication & 16 & 28.5 \\
\hline \multicolumn{3}{|l|}{ Findings $(n=53) *$} \\
\hline Hiatal hernia & 37 & 69.8 \\
\hline Esophagitis & 16 & 30.2 \\
\hline Reflux laryngitis & 7 & 13.7 \\
\hline Gastritis & 5 & 9.4 \\
\hline Barrett's esophagust & 3 & 5.7 \\
\hline Schatzki's ring & 1 & 1.9 \\
\hline More than 1 finding & 22 & 41.5 \\
\hline \multicolumn{3}{|l|}{ Clinical management $(n=53)^{*}$} \\
\hline $\begin{array}{l}\text { At least } 1 \text { change in clinical } \\
\text { management }\end{array}$ & 42 & 73.6 \\
\hline Medication added/deleted & 35 & 66.0 \\
\hline $\begin{array}{l}\text { Esophagogastroduodenoscopy } \\
\text { requested }{ }^{\ddagger}\end{array}$ & 8 & 9.4 \\
\hline Radiograph requested & 3 & 5.7 \\
\hline Consultation requested & 2 & 3.8 \\
\hline \multicolumn{3}{|c|}{$\begin{array}{l}\text { * Unsedated ultrathin esophagoscopy (UUE) was not completed in } 3 \text { patients. } \\
\text { † Confirmed on subsequent esophagogastroduodenoscopy with biopsy. } \\
\text { ‡ } 3 \text { patients could not tolerate UUE, Barrett's esophagus was suspected in } 3 \\
\text { patients, } 2 \text { patients had other pathologic findings requiring biopsy, eg, esopha- } \\
\text { geal nodule and gastric polyp. }\end{array}$} \\
\hline
\end{tabular}

color chip similar to that used in standard endoscopes and, therefore, is not as susceptible to image distortion as is the older color wheel technology.

There are several factors that may be useful to predict successful UUE, including age, sex, anxiety level, endoscope diameter, and decreased pharyngeal sensitivity. ${ }^{16-19} \mathrm{~A}$ recent study ${ }^{14}$ suggested that higher levels of anxiety, as assessed by the Profile of Mood States Tension/Anxiety subscale (POMS-SF T/A), ${ }^{20}$ are associated with a lower likelihood of completing UUE. Additionally, the finger-to-throat test to measure gag reflex has been suggested as a way to select patients for unsedated upper endoscopy. ${ }^{21}$ Clearly, a convenient and efficient way to preselect patients with a high likelihood of successful UUE is needed.

Because UUE can be used to evaluate only the proximal stomach, physicians might worry about missing pathologic findings in the stomach or duodenum. A recent study, however, reported that UUE is sufficient, ie, there is very low risk $(<1 \%)$ of missing important findings for GERD patients who do not have daily abdominal pain and nausea or a history of ulcer disease. ${ }^{22}$ 
Six percent of our sample had Barrett's esophagus diagnosed according to standard endoscopic criteria of columnar epithelium in the distal esophagus. The prevalence of Barrett's esophagus in primary care populations with chronic GERD symptoms is unknown. In one study, Barrett's esophagus was undetected until autopsy in $71 \%$ of the cases. ${ }^{23}$ A prospective trial of male veterans older than 50 years who participated in flexible sigmoidoscopy for colon cancer screening found the prevalence of Barrett's esophagus in asymptomatic patients to be $25 \%{ }^{24}$ In contrast, an Italian cohort study observed 177 patients with Barrett's esophagus for 5.5 years and reported a low rate of progression to dysplastic changes or esophageal adenocarcinoma. ${ }^{25}$ Screening efforts for Barrett's esophagus are most important for patients who have the greatest risk of developing esophageal cancer, eg, male, severe and chronic reflux symptoms, and obesity. ${ }^{26}$ Most experts agree that young patients (younger than 40 years) with mild reflux symptoms can be cared for without endoscopy. ${ }^{27}$

For UUE to be effective as a screening tool for Barrett's esophagus, patients need immediate access to the procedure, which may require that additional primary care physicians be trained in this procedure..$^{28} \mathrm{~A}$ recent study suggested that screening chronic GERD patients for Barrett's esophagus using UUE is cost-effective, ${ }^{29}$ and UUE accurately detects Barrett's esophagus when compared with conventional EGD. ${ }^{10-12}$ Although in the past, experts have concluded that there is insufficient evidence to warrant screening for Barrett's esophagus or esophageal cancer, ${ }^{26,30}$ the emerging data on UUE warrant reconsideration of the guidelines that cited a lack of evidence for screening for Barrett's esophagus.

We contend that screening high-risk patients who have chronic GERD symptoms is analogous to the call in the 1980s for family physicians to screen for colon polyps and cancer by flexible sigmoidoscopy. ${ }^{31,32}$ Those early reports called for widespread adoption of flexible sigmoidoscopy in family medicine residency training programs. Likewise, we suggest that widespread adoption of UUE by family medicine residency programs would add to the diagnostic armamentarium of family physicians in treating patients with chronic GERD symptoms, including screening for Barrett's esophagus and esophageal cancer. At our institution, as part of our performance-based criteria, we require family medicine residents to conduct 25 supervised UUEs with successful esophageal intubation and retroflexion maneuvers. An earlier study ${ }^{12}$ reported 10 supervised UUEs by nurse practitioners who had experience with EGD.

In addition to the potential diagnostic capabilities of UUE, this procedure may have economic viability in primary care. We successfully billed for UUE and collected reimbursements for CPT code 43200 (esophagoscopy) at rates of $\$ 79$ for Medicare, $\$ 96$ to $\$ 131$ for Medicaid, and $\$ 253$ to $\$ 382$ for private insurance. Although the XEF$140 \mathrm{Y} 1$ endoscope is not yet commercially available, its diameter is comparable to that of other esophagoscopes that are widely available. According to the manufacturer, the estimated price of the XEF-140Y1 endoscope, including monitor, light source, and processor, is approximately \$55,000 (Mori T, Olympus America, Inc, Melville, NY, oral communication, March 8, 2005.)

\section{Limitations}

All procedures were performed in an academic university-based medical center. Patients referred in this case series may not be representative of many primary care practices in that $70 \%$ of our patients were white nonHispanic, and $64 \%$ had private insurance. In addition, there may have been selection bias, as all study patients expected a diagnostic procedure as recommended by their primary care physician. No information was collected regarding the total number of patients referred and the number of patients that did not keep their appointments. All procedures were performed by an endoscopist with experience in unsedated endoscopy. Finally, we did not assess patients' anxiety levels before or during UUE or assess patients' willingness to undergo another UUE.

\section{Future Studies}

This report describes UUE by a family physician in a primary care clinic. Initial studies should examine family medicine residents' interest in performing UUE in future practices and the capacity of family medicine faculty to meet this training need. Additionally, a future study is needed to determine the financial viability of UUE in primary care, comparing the financial outlay with reimbursements. If interest in UUE in primary care is confirmed, then large randomized controlled trials are needed to determine the utility, safety, accuracy, and cost-effectiveness of UUE in primary care. Future studies should focus on validating a preselection instrument to help assess which patients would have a high likelihood for a successful UUE and would, therefore, not require additional endoscopy. The importance of preselection of patients for UUE may help to determine the cost-effectiveness of this procedure. In other words, most attempted UUEs must be completed without the need for additional referrals or endoscopy. Additional studies of the prevalence of Barrett's esophagus in primary care patients with chronic GERD symptoms need to be performed, which may further determine the need for a readily available screening tool in primary care for Barrett's esophagus. Finally, other studies should systematically evaluate residency training of UUE and determine performance-based criteria. 
To read or post commentaries in response to this article, see it online at http://www.annfammed.org/cgi/content/full/3/2/126.

Key words: Endoscopy, gastrointestinal; family practice

Submitted September 9, 2004; submitted, revised, November 22, 2004; accepted November 29, 2004.

\section{References}

1. Pope CE II. Acid-reflux disorders. N Engl J Med. 1994;331:656-660.

2. Spechler SJ, Goyal RK. Barrett's esophagus. N Engl J Med. 1986;315: 362-371.

3. Wong R, Malthaner R. Esophageal cancer: a systematic review. Curr Probl Cancer. 2000;24:297-373.

4. Streitz JM Jr, Andrews CW Jr, Ellis FH Jr. Endoscopic surveillance of Barrett's esophagus. Does it help? J Thorac Cardiovasc Surg. 1993; 105:383-388.

5. Aviv JE, Takoudes TG, Ma G, Close LG. Office-based esophagoscopy: a preliminary report. Otolaryngol Head Neck Surg. 2001;125:170-175.

6. Postma GN, Bach KK, Belafsky PC, Koufman JA. The role of transnasal esophagoscopy in head and neck oncology. Laryngoscope. 2002; 112:2242-2243.

7. Darwin P, Zangara J, Heller T, Haluszka O, Laurin J. Unsedated esophagoscopy for the diagnosis of esophageal varices in patients with cirrhosis. Endoscopy. 2000;32:971-973.

8. Catanzaro A, Faulx A, Pfau PR, et al. Accuracy of a narrow-diameter battery-powered endoscope in sedated and unsedated patients. Gastrointest Endosc. 2002;55:484-487.

9. Catanzaro A, Faulx A, Isenberg GA, et al. Prospective evaluation of 4-mm diameter endoscopes for esophagoscopy in sedated and unsedated patients. Gastrointest Endosc. 2003;57:300-304.

10. Saeian K, Staff DM, Vasilopoulos S, et al. Unsedated transnasal endoscopy accurately detects Barrett's metaplasia and dysplasia. Gastrointest Endosc. 2002;56:472-478.

11. Mokhashi MS, Wildi SM, Glenn TF, et al. A prospective, blinded study of diagnostic esophagoscopy with a superthin, stand-alone, batterypowered esophagoscope. Am J Gastroenterol. 2003;98:2383-2389.

12. Wildi SM, Wallace MB, Glenn TF, Mokhashi MS, Kim CY, Hawes RH. Accuracy of esophagoscopy performed by a non-physician endoscopist with a 4-mm diameter battery-powered endoscope. Gastrointest Endosc. 2003;57:305-310.

13. Belafsky PC, Postma GN, Daniel E, Koufman JA. Transnasal esophagoscopy. Otolaryngol Head Neck Surg. 2001;125:588-589.

14. Faulx AL, Catanzaro A, Zyzanski S, et al. Patient tolerance and acceptance of unsedated ultrathin esophagoscopy. Gastrointest Endosc. 2002; 55:620-623.

15. Nelson DB, Block KP, Bosco JJ, et al. Technology status evaluation report: ultrathin endoscopes esophagogastroduodenoscopy: Gastrointest Endosc. 2000;51:786-789.
16. Mulcahy HE, Kelly P, Banks M, Farthing M, Fairclough PD, Kumar P. Factors associated with tolerance to unsedated upper gastrointestinal endoscopy. Gastrointest Endosc. 1998;47:AB56.

17. Froehlich F, Schwizer W, Thorens J, Kohler M, Gonvers JJ, Fried M. Conscious sedation for gastroscopy: patient tolerance and cardiorespiratory parameters. Gastroenterology. 1995;108:697-704.

18. Tan CC, Freeman JG. Throat spray for upper gastrointestinal endoscopy is quite acceptable to patients. Endoscopy. 1996;28:277-282.

19. Abraham N, Barkun A, Larocque M, et al. Predicting which patients can undergo upper endoscopy comfortably without conscious sedation. Gastrointest Endosc. 2002;56:180-189.

20. Curran SL, Andrykowski MA, Studts JL. Short form of the profile of mood states (POMS-SF): psychometric information. Psychological Assess. 1995; 7:80-83.

21. Ladas SD, Raptis SA. Selection of patients for upper gastrointestinal endoscopy without sedation. The finger-throat test. Ital J Gastroenterol. 1986;18:162-165.

22. Wildi SM, Glenn TF, Woolson RF, Wang W, Hawes RH, Wallace MB. Is esophagoscopy alone sufficient for patients with reflux symptoms? Gastrointest Endosc. 2004;59:349-354.

23. Cameron AJ, Zinsmeister AR, Ballard DJ, Carney JA. Prevalence of columnar-lined (Barrett's) esophagus. Comparison of populationbased clinical and autopsy findings. Gastroenterology. 1990;99:918922.

24. Gerson LB, Shetler K, Triadafilopoulos G. Prevalence of Barrett's esophagus in asymptomatic individuals. Gastroenterology. 2002;123:461-467.

25. Conio M, Blanchi S, Lapertosa G, et al. Long-term endoscopic surveillance of patients with Barrett's esophagus. Incidence of dysplasia and adenocarcinoma: a prospective study. Am J Gastroenterol. 2003;98:1931-1939.

26. Gerson LB, Triadafilopoulos G. Screening for esophageal adenocarcinoma: an evidence-based approach. Am J Med. 2002;113:499-505.

27. Sampliner RE. Updated guidelines for the diagnosis, surveillance, and therapy of Barrett's esophagus. Am J Gastroenterol. 2002;97:1888-1895.

28. Devault KR. Ultrathin endoscopy without sedation: is this the future of esophagology? Am J Gastroenterol. 2003;98:2342-2344.

29. Nietert PJ, Silverstein MD, Mokhashi MS, et al. Cost-effectiveness of screening a population with chronic gastroesophageal reflux. Gastrointest Endosc. 2003;57:311-318.

30. Sharma P, McQuaid K, Dent J, et al. A critical review of the diagnosis and management of Barrett's esophagus: the AGA Chicago Workshop. Gastroenterology. 2004;127:310-330.

31. Johnson RA, Quan M, Rodney WM. Flexible sigmoidoscopy. J Fam Pract. 1982;14:757-763.

32. Winawer SJ, Cummins R, Baldwin MP, Ptak A. A new flexible sigmoidoscope for the generalist. Gastrointest Endosc. 1982;28:233-236. 